\title{
Influence of Blood Biochemistry, Auditory and Musculoskeletal Well-being of Professional Drivers on Road Accidents
}

\author{
${\text { Mehdi Jahangiri }{ }^{1} \text {, Ali Karimi }}^{2 *}$ and Samira Eslamizad ${ }^{3}$ \\ ${ }^{1}$ Research Center for Health Sciences, Shiraz University of Medical Sciences, Iran \\ ${ }^{2}$ Department of Occupational Health, Tehran University of Medical Sciences, Iran \\ ${ }^{3}$ Food Safety Research center, Shahid-Beheshti University of Medical Sciences, Tehran, Iran
}

Submission: April 26, 2017; Published: May 05, 2017

*Corresponding author: Ali Karimi, Department of Occupational Health, School of Public Health, Tehran, University of Medical Sciences, Tehran, Iran, Email: a_karimi@sina.tums.ac.ir

Abstract

Introduction: Drivers health may affect their safe performance. The aim of this study was to characterize a population of professional drivers with regard to the association of accident occurrence with physical and auditory wellbeing and blood biochemistry.

Methods: Using validated questionnaire, information about musculoskeletal complaints, demographic features, smoking habits, age, job experience, accident occurrence, job consent, self-perceived job stress and fatigue were obtained from 403 professional drivers. The audiometric testing of both ears of the selected subjects was conducted at frequencies of 250, 500, 1000, 2000,3000, 4000, 6000 and 8000 $\mathrm{Hz}$. Blood samples were collected and important blood factors were analyzed using validated biochemistry tests.

Results: All participants were male, with a mean age of $37 \pm 9.5$ years, mean BMI of $24.5 \pm 3.9 \mathrm{Kg} / \mathrm{m}^{2}$, mean total cholesterol of $210 \pm$ $39 \mathrm{mg} / \mathrm{dL}$, mean triglyceride level of $205 \pm 88 \mathrm{mg} / \mathrm{dL}$, and fasting blood sugar (FBS) was above $120 \mathrm{mg} / \mathrm{dL}$ in 261 subjects (69\%). $27.5 \%$ of the subjects experienced at least on road accident and they showed weaker auditory sense and higher blood triglyceride (not statistically significant). Significant association between PMSC (prevalence of musculoskeletal complaints) with drivers fatigue was discovered ( $\mathrm{P}<0.001)$. Also positive associations were found between road accident occurrence and musculoskeletal problems especially in neck, upper back and ankles $(\mathrm{P}<0.05)$.

Conclusion: It can be said that physical well-being influences the safe operation of professional drivers. Among investigated parameters in this study, Ergonomics risk factor showed the best association with road accident, and musculoskeletal problems can be good predictors of road accident liability.

Practical Application: Application of corrective strategies in field of occupational ergonomics and health surveillance programs for professional drivers can be helpful for reducing road accidents.

Keywords: Blood biochemistry; Hearing; Musculoskeletal complaints; Professional drivers; Road accident

\section{Highlights}

a. Drivers health condition especially musculoskeletal wellbeing associate with road accident

b. Musculoskeletal complaints are strongly associated with drivers falling at the wheel (fatigue).

c. Drivers who experienced road accident, showed weaker auditory sense and higher blood triglyceride

d. Smokers usually experience more musculoskeletal problems and road accidents.

\section{Introduction}

The challenges to forecast individual changes in road accident liability have paid a little extent of attention in traffic safety investigations. One of the predictors that have received fair attention is health-related problems [1]. It is known that professional drivers are exposed to various forms of job-related stress. The health of the driver is a critical factor in driving performance [2-4]. Some studies showed that professional drivers had improper occupational health indicators (e.g., cholesterol levels, blood pressure and body weight). The 
prevalence of cardiovascular disease, gastrointestinal disorders, and musculoskeletal problems in this group of people was greater than the others [4-5].

According to the literatures coronary vessels hardness (Ischaemic heart disease) has found to be more with lifestyle and characteristics of professional driver (e.g., male, smoking, Overweight, high cholesterol levels and blood pressure) [6]. Obesity as a cardiovascular disease risk factor has been involved lengthwise with driver's irregular nutrition behaviors, physical inactivity at, smoking and even reduced social interacting [7]. Long and Perry (1985), reported that $42 \%$ of Russian bus driver had hypertension with a positive association between hypertension and work duration [6].

Noise and vibration are the harmful physical factors that may affect the health of drivers. This is particularly distressing for professional drivers who experience higher tension levels from the traffic conditions and time pressures of the job [2]. Exceeding noise usually causes in reducing of hearing sense (increase of hearing threshold levels) [8]. Away from the known concerns of hearing loss and the probability of permanent tinnitus, there is increasing confirmation that workers exposed to high level of occupational noise are also at greater risk of accident. Somehow, it would seem that noise exposure and hearing loss may interact to interfere with the safe occupational performance $[9,10]$.

Professional drivers are a group of workers that have been reported widely as being at an increased risk of musculoskeletal disorders. Musculoskeletal complaints among bus drivers compared to other occupational groups indicate that musculoskeletal disorders are a major work-related health problem for bus drivers. Frequently reported complaints relate to the lower and upper part of the back, shoulders, neck and the knees [11,12]. Several factors have been identified as being important occupational stressors contributing to the onset and development of musculoskeletal disorders but the most common in transportation industry include heavy physical work, repetitive motions, sustained and demanding postures, vibration, temperature extremes and workplace stress [3].

Musculoskeletal disorders among professional drivers have been the subjects of several studies. Anker Jensen reported that intervertebral disc disorders were more common among professional drivers [13]. Another study showed significant association between low back pain and ergonomic factors among professional bus drivers. Chen et al. investigated Occupational factors of taxi drivers in Taiwan with regard to low back pain. They found that driving time, frequent bending/twisting activities while driving, job stress and job dissatisfaction were the major occupational factors significantly associated with higher and lower back pain prevalence in taxi drivers [14]. In comparing occupational risk factors, the WHO listed the risks of experiencing low back pain with risk score ranging from 1.83 to 5.49 for bus drivers, trucks and tractors drivers relative to a baseline risk of 1.0 for office clerical workers [15].
On the other hand, work-related road safety is one of the key areas of concern for all societies [16]. Several factors such as the health status of individuals and human error play a role in the occurrence of accidents, but human factors apparently account for $65 \%$ of all U.K. road accidents [6]. Human error is affected by internal or external factors like illness and other health problems. Professional drivers had a higher percentage of serious injuries and severe permanent impairments as compared to other occupational groups [3]. Driver fatigue is a particularly prevalent cause of work-related road traffic collisions resulting in injury or death [16]. It is accounting for up to $20 \%$ of serious accidents on motorways and monotonous roads in Britain [17]. Little studies discussed association of musculoskeletal disorders and traffic accident among professional drivers.

Traffic accidents in known as the second cause of death after cardiovascular diseases in Iran and this country has a high rank regarding to traffic fatalities in the world, so Iranian society seems to be a good field for investigation of root cause of road crashes. The present study was conducted to investigate occupational conditions of professional drivers in order to explore and highlight health aspects of professional drivers and their influence on road accident.

\section{Methods}

\section{Subjects and Design}

This cross-sectional study was conducted among professional drivers working on transpiration system of Iran. Data were collected from professional driver's candidate to receive driving health certificate. A total of 500 full-time male drivers were randomly recruited to the study, regardless of their health status and the presence of musculoskeletal disorders. Since the number of female drivers was negligible, they were excluded from the study. Drivers that have engaged in additional businesses have been omitted. Furthermore, drivers who had a history of genetic sickness and adulatory problems caused by the explosion, accidents, medication use, etc., have been excluded from the research. Drivers with a history of traumatic road or work accidents were also excluded from the study. The subjects that had not given complete information about their working conditions were also excluded. Data were collected for 500 drivers but according to the criteria, 20 percent of the subjects were omitted. Each of the drivers was briefed regarding the questionnaire and asked to fill in a consent form to participate in the study. At the end, each of the questionnaires was checked by the research assistant to verify that all the questions had been answered. The population was relatively cooperative, and 403 completed questionnaires recognized qualified for analysis.

\section{Blood Tests}

Base on a national procedure, each participant was interviewed by qualified physicians and completed a questionnaire covering data on demographics, anthropometric summary, individual characteristics associated with the previous 
medical history. Then the subjects' blood pressure (BP) was measured, by means of a standard mercury sphygmomanometer with an appropriate cuff calibrated. Two successive diastolic and systolic blood pressures were logged on the right arm. Blood samples were collected into vacationer tubes between 8:00 to 10:00 a.m. All the subjects had fasted about 10h. Fast blood sugar (FBS) and other blood parameters were measured by skilled nurses at a clinical analysis lab, according to standard techniques. Blood sugar and lipids, comprising triglycerides, and high-density lipoproteins were evaluated using a BT-3000 auto-analyzer (Biotecnica, Rome, Italy). The cholesterol and triglyceride were assessed using enzymatic examinations with commercially accessible kits (Pars Azmoon Inc., Iran). Fasting blood sugar more than $120 \mathrm{mg} / \mathrm{dl}$ was defined abnormal in this study. All samples were evaluated when daily internal quality control met the acceptable criteria.

\section{Audiometry Tests}

Audiometry in frequencies of 250, 500, 1000, 2000, 3000, 4000,6000 , and $8000 \mathrm{~Hz}$ were performed by a specialized audiologist in compliance with the Guidelines for audiologic screening [18].

\section{Questionnaire}

For assessment of musculoskeletal symptoms within the last 12 months in neck, shoulders, upper back, elbows, wrists/hands, lower back, hip, knees and ankles a Swedish version of the Nordic Questionnaire, which includes items with dichotomized response alternatives regarding symptoms (ache, pain, or discomfort) originating from different regions of the musculoskeletal system, was used [19]. In addition, the questionnaire included background information such as, age, height, weight, marital status, education level, smoking habits, exercise, and working information such as job experience, sort of vehicle, age of vehicle, continuous driving duration, total driving duration per 24 hours, night driving duration per 24 hours, total rest (sleep) per 24 hours, background road accident occurrence, Falling asleep at the wheel (fatigue) and health education. For validity and reliability testing of the questionnaire, a pilot study was tried on 15 male professional drivers to control its easiness of use and period of time to complete the questionnaire. The pilot samples were also requested to decide if there were matters of importance that were not involved in the questionnaire. The internal reliability of the questionnaire was surveyed using Cronbach's alpha. Testing items on the questionnaire shown satisfactory coefficient alpha of 0.7 or more.

\section{Statistical analysis}

The Kolmogorov-Smirnov normality test was used to determine the homogeneity of the population of drivers. Descriptive analysis was then performed, with the results expressed as either mean and standard deviation values or absolute number and percentage, when appropriate. In order to determine analytical analysis, all the subjects were divided into two or three subgroups according to the variable in question.
For the musculoskeletal symptoms one non-symptom group and one symptom group were considered. The T-test was used for comparing means of Continuous variables. Pearson chi-square tests were used in statistical analysis and the associations were described in the results. Significance refers to the $95 \%$ confidence interval; and SPSS 17 was used for the statistical calculations.

\section{Results}

Personal characteristics (demographics and personal health-related factors) and occupational factors of the subjects are presented in (Table 1). All participants were male, with a mean age of $37 \pm 9.5$ years, mean weight of $74.4 \pm 13.7 \mathrm{~kg}$, mean BMI $24.5 \pm 3.9 \mathrm{Kg} / \mathrm{m}^{2}$; mean total cholesterol was $210 \pm 39 \mathrm{mg}$ / $\mathrm{dL}$, mean triglyceride level was $205 \pm 88 \mathrm{mg} / \mathrm{dL}$, and fasting blood sugar (FBS) was above $120 \mathrm{mg} / \mathrm{dL}$ in 261 subjects (69\%). $27.5 \%$ of the subjects experienced at least on road accident. Among them, 400 drivers (99.3\%) reported having one or more musculoskeletal complaints during the previous year. Also (Table 1) shows that the average cholesterol and triglyceride of the subjects are higher than normal range but hearing threshold of the drivers in $1000 \mathrm{~Hz}$ average laid normal range ( $<25 \mathrm{~dB}$ ).

Table 1: Basic information and health-related factors of professional drivers in this study.

\begin{tabular}{|c|c|c|c|c|}
\hline & $\begin{array}{c}\text { Mean } \\
(n=403)\end{array}$ & $\begin{array}{l}\text { Standard } \\
\text { deviation }\end{array}$ & Maximum & Minimum \\
\hline Age (year) & 37 & 9.5 & 20 & 66 \\
\hline $\begin{array}{l}\text { Driving } \\
\text { Experience } \\
\text { (year) }\end{array}$ & 13.17 & 8.5 & 40 & 1 \\
\hline $\begin{array}{l}\text { Driving } \\
\text { duration }\end{array}$ & 10 & 2.8 & 14 & 5 \\
\hline BMI & 24.45 & 3.9 & 51 & 16 \\
\hline FBS & 109 & 15.7 & 227 & 71 \\
\hline $\begin{array}{l}\text { Triglycerides } \\
\text { (mg/dL) }\end{array}$ & 205 & 88 & 492 & 50 \\
\hline $\begin{array}{c}\text { Total } \\
\text { cholesterol } \\
(\mathrm{mg} / \mathrm{dL})\end{array}$ & 210 & 39 & 321 & 117 \\
\hline SBP (mmHg) & 125 & 7.4 & 175 & 110 \\
\hline DBP (mmHg) & 72 & 5.7 & 110 & 60 \\
\hline $\begin{array}{c}\text { Hearing } \\
\text { threshold (left, } \\
1 \mathrm{kHz})\end{array}$ & 17 & 5.7 & 60 & 10 \\
\hline $\begin{array}{l}\text { Hearing } \\
\text { threshold ( } \\
\text { right, 1kHz) }\end{array}$ & 16 & 5.3 & 45 & 10 \\
\hline
\end{tabular}

Mean difference of quantitative variables between drivers with and without road accidents were investigated using t-test. The results in (Table 2) revealed that younger drivers reported more road accident but this fact is not statistically significant $(\mathrm{P}>0.05)$. Also none of the blood parameters showed significant association with road accident, but higher blood triglyceride and higher BMI were seen in drivers who had been reported road 
accident. There was not any significant difference of auditory sense between two groups of drivers (with and without road accident) but drivers with road accident showed higher hearing threshold levels $(\mathrm{P}>0.05)$. The results in (Table 2$)$ showed that there are significant relationship between accident occurrence and Job stress, Job consent, continues driving and age of vehicle $(\mathrm{P}<0.05)$.

Table 2: Statistical assessment of relationships between some health's related factors and road accident among professional drivers.

\begin{tabular}{|c|c|c|c|c|c|c|c|c|c|}
\hline & \multicolumn{3}{|c|}{ Experienced no road accident } & \multicolumn{3}{|c|}{ Experienced road accident } & \multicolumn{3}{|c|}{ Sig (p value) } \\
\hline & $\mathbf{n}$ & Mean & SD & $\mathbf{n}$ & Mean & SD & MD & t & \\
\hline Age (year) & 292 & 37.8 & 12.5 & 109 & 36.6 & 9 & 1.2 & 401 & 0.36 \\
\hline $\begin{array}{l}\text { Driving } \\
\text { experience } \\
\text { (year) }\end{array}$ & 285 & 13.3 & 10 & 111 & 14.3 & 9 & 1 & 403 & 0.36 \\
\hline Job stress & 266 & 3.5 & 3 & 69 & 4.5 & 3 & 1 & 362 & $0.008^{*}$ \\
\hline Job consent & 275 & 5.1 & 3.3 & 99 & 4.2 & 3 & 0.9 & 374 & $0.019^{*}$ \\
\hline $\begin{array}{l}\text { Continues } \\
\text { driving (hr) }\end{array}$ & 289 & 4.8 & 2 & 110 & 5.2 & 1.7 & 0.4 & 399 & $0.05^{*}$ \\
\hline $\begin{array}{c}\text { Vehicle } \\
\text { age(year) }\end{array}$ & 281 & 6.2 & 4.6 & 104 & 7.3 & 4.8 & 1.13 & 385 & $0.037^{*}$ \\
\hline BMI & 291 & 24.1 & 4.1 & 108 & 24.6 & 3.4 & 0.43 & 399 & 0.33 \\
\hline Hemoglobin & 291 & 15 & 1.3 & 109 & 15.2 & 1.5 & 0.2 & 400 & 0.55 \\
\hline Hematocrit & 291 & 45 & 3.2 & 109 & 45.2 & 3 & 0.2 & 400 & 0.8 \\
\hline WBC & 291 & 6.6 & 1.8 & 109 & 6.7 & 1.7 & 0.1 & 400 & 0.71 \\
\hline $\mathrm{RBC}$ & 291 & 5.47 & 0.7 & 109 & 5.55 & 0.7 & 0.07 & 400 & 0.3 \\
\hline FBS & 291 & 110 & 15 & 109 & 107 & 19 & 3 & 400 & 0.17 \\
\hline Cholesterol & 291 & 212 & 37 & 109 & 206 & 43 & 6 & 400 & 0.18 \\
\hline Triglyceride & 291 & 205 & 92 & 109 & 209 & 93 & 4 & 400 & 0.76 \\
\hline SBP & 291 & 125 & 7.5 & 108 & 124 & 7.4 & 1 & 400 & 0.17 \\
\hline DBP & 291 & 71.5 & 5.5 & 108 & 71.8 & 6 & 0.3 & 400 & 0.7 \\
\hline
\end{tabular}

*(independent t-test, P<0.05), MD: Mean Difference, SD: Standard Deviation

From the 9 body parts questionnaires, the lower back had the highest complain of musculoskeletal problems $(25.2 \%)$, followed by the knees, neck, ankles, shoulders, upper back, hip, wrists/hands and elbows. Complaints involving the wrists/ hands and elbow showed lower prevalence rates of $9.2 \%$ and $6.4 \%$, respectively. Also among our four groups of professional drivers, bus drivers showed higher PMSC neck, lower back and knees compared other vehicle drivers but this difference was not statistically significant. The Pearson chi-square test showed that drivers with fatigue (falling asleep at the wheel) and feel sleepy on the role were more likely to be involved in road accident $(\mathrm{P}<0.05)$. The association of getting involved in road accident and sense of discomfort from car noise remained statistically significant $(\mathrm{P}<0.05)$. Also drivers who smoke and eat junk food while driving reported more road accidents $(\mathrm{P}<0.05)$ (Table 3$)$.

Table 3: Comparison of professional drivers with and without road accident regarding to some occupational risk factors.

\begin{tabular}{|c|c|c|c|c|c|c|}
\hline & $\begin{array}{c}\text { Accident } \\
\text { experience }\end{array}$ & $\begin{array}{c}\text { Accident } \\
\text { experience }\end{array}$ & Total \% & Total (n) & Total \% & $\begin{array}{c}\text { Chi-square test } \\
\text { (P value) }\end{array}$ \\
\hline & & no & Yes & & & \\
\hline \multirow{4}{*}{$\begin{array}{l}\text { Falling asleep at } \\
\text { the wheel }\end{array}$} & No & 226 & 50 & 276 & 71.1 & \\
\hline & Yes & 63 & 49 & 112 & 28.9 & $\mathrm{P}<0.001^{* *}$ \\
\hline & Total (n) & 289 & 99 & 388 & 100 & \\
\hline & Total \% & 74.5 & 25.5 & 100 & & \\
\hline \multirow{4}{*}{$\begin{array}{l}\text { Feel sleepy on the } \\
\text { role }\end{array}$} & No & 114 & 30 & 144 & 36.2 & $0.022^{*}$ \\
\hline & Yes & 174 & 80 & 254 & 63.8 & \\
\hline & Total (n) & 288 & 110 & 398 & 100 & \\
\hline & Total \% & 72.4 & 27.6 & 100 & & \\
\hline
\end{tabular}




\begin{tabular}{|c|c|c|c|c|c|c|}
\hline \multirow{4}{*}{ Smoking } & No & 206 & 73 & 279 & 76.6 & \\
\hline & Yes & 53 & 32 & 85 & 23.4 & $0.041^{*}$ \\
\hline & Total (n) & 259 & 105 & 364 & 100 & \\
\hline & Total \% & 71.2 & 28.8 & 100 & & \\
\hline \multirow{4}{*}{$\begin{array}{l}\text { Discomfort from } \\
\text { car noise }\end{array}$} & No & 154 & 38 & 192 & 49.1 & \\
\hline & Yes & 138 & 61 & 199 & 50.9 & $0.009 *$ \\
\hline & Total (n) & 292 & 99 & 391 & 100 & \\
\hline & Total \% & 74.7 & 25.3 & 100 & & \\
\hline \multirow{4}{*}{$\begin{array}{l}\text { Eating junk food } \\
\text { while driving }\end{array}$} & No & 111 & 28 & 139 & 36.6 & \\
\hline & Yes & 172 & 69 & 241 & 63.4 & $0.043^{*}$ \\
\hline & Total (n) & 283 & 97 & 380 & 100 & \\
\hline & Total \% & 74.5 & 25.5 & 100 & & \\
\hline
\end{tabular}

${ }^{*}($ Pearson chi-square, $\mathrm{P}<0.05),{ }^{* *}($ Pearson chi-square, $\mathrm{P}<0.001)$.

The results of a comparison between drivers with and without previous involvement in road crashes regarding to PMSC are shown in (Figure 1). Analysis of the 12 months PMSC stratified by having traffic accident occurrence, revealed that drivers with musculoskeletal complaints specially in neck, upper back and ankles more frequently experienced traffic accidents $(\mathrm{P}<0.05)$ (Table 4). "Falling asleep at the wheel" considered the most important outcomes of occupational fatigue regarding to professional drivers and probably there is some contribution between fatigue and musculoskeletal complaints. So stratified by frequency of "falling asleep at the wheel", the crude estimates of 1-year PMSC were shown in (Table 4). The data concerning drivers' fatigue indicated that there is high significant association between musculoskeletal complaints and drivers' "falling asleep at the wheel" frequency in all of the body limbs in the questionnaire $(\mathrm{P}<0.01)$.

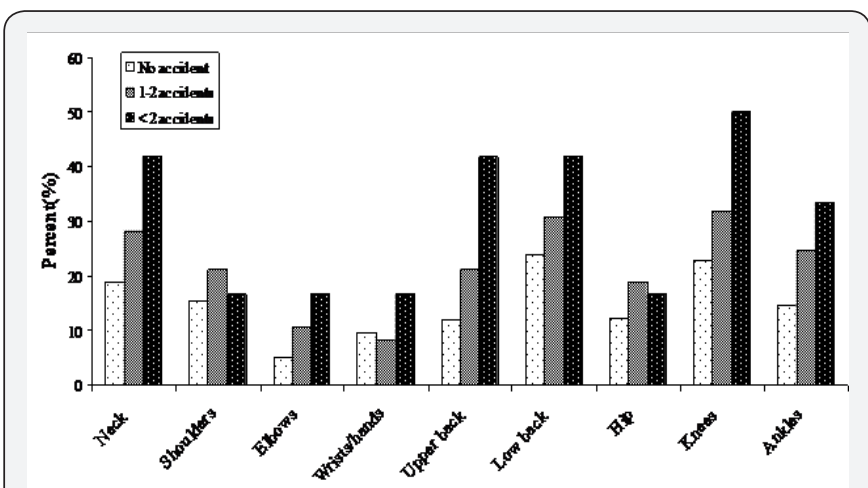

Figure 1: The prevalence of musculoskeletal complains among drivers with and without previous traffic accident experience.

Table 4: Statistical association of road accident with accident occurrence and drivers fatigue.

\begin{tabular}{|c|c|c|c|c|c|c|c|c|}
\hline & & \multicolumn{2}{|c|}{ Accident experience } & \multirow{2}{*}{$\begin{array}{c}\text { Chi-square } \\
\text { (P value) }\end{array}$} & & \multicolumn{2}{|c|}{$\begin{array}{l}\text { Falling asleep at the } \\
\text { wheel(fatigue) }\end{array}$} & \multirow{2}{*}{$\begin{array}{r}\text { Chi-square } \\
\text { (P value) }\end{array}$} \\
\hline & & $\begin{array}{c}\text { No } \\
\text { n(\%) }\end{array}$ & $\begin{array}{c}\text { Yes } \\
\text { n(\%) }\end{array}$ & & & $\begin{array}{c}\text { No } \\
\text { n(\%) }\end{array}$ & $\begin{array}{c}\text { Yes } \\
\text { n(\%) }\end{array}$ & \\
\hline \multirow{2}{*}{ Neck } & No & $55(18.8)$ & $30(27.3)$ & $0.044^{*}$ & No & $45(16.3)$ & $40(35.7)$ & \multirow{2}{*}{$\mathrm{P}<0.001^{* *}$} \\
\hline & Yes & $238(82.2)$ & $80(72.7)$ & & Yes & $231(83.7)$ & $72(64.3)$ & \\
\hline \multirow{2}{*}{ Shoulders } & No & $45(15.4)$ & $22(20)$ & 0.17 & No & $36(13)$ & $29(25.9)$ & \multirow{2}{*}{$0.002^{*}$} \\
\hline & Yes & $248(84.6)$ & $88(80)$ & & Yes & $240(87)$ & $83(74.1)$ & \\
\hline \multirow{2}{*}{ Upper back } & No & $35(11.9)$ & $24(21.8)$ & $0.011^{*}$ & No & $25(9.1)$ & $33(29.5)$ & \multirow{2}{*}{$\mathrm{P}<0.001^{* *}$} \\
\hline & Yes & 258(88.1) & $86(78.2)$ & & Yes & $251(90.9)$ & $79(70.5)$ & \\
\hline \multirow{2}{*}{ Elbows } & No & $15(5.1)$ & $11(10)$ & 0.065 & No & $11(4)$ & $14(12.5)$ & \multirow{2}{*}{$0.003^{*}$} \\
\hline & Yes & $278(94.9)$ & $99(90)$ & & Yes & $265(96)$ & $98(87.5)$ & \\
\hline \multirow{2}{*}{ Lower back } & No & $70(23.9)$ & $32(29.1)$ & 0.17 & No & $55(19.9)$ & $45(40.2)$ & \multirow{2}{*}{$\mathrm{P}<0.001^{* *}$} \\
\hline & Yes & 223(76.1) & 78(70.9) & & Yes & $221(80.1)$ & 67(59.8) & \\
\hline \multirow{2}{*}{ Wrists/hands } & No & $28(9.6)$ & $9(8.2)$ & 0.42 & No & $18(6.5)$ & $19(17)$ & \multirow{2}{*}{$0.002^{*}$} \\
\hline & Yes & $265(90.4)$ & 101(91.8) & & Yes & $258(93.5)$ & $93(83)$ & \\
\hline \multirow{2}{*}{ Hip/leg } & No & $36(12.3)$ & $18(16.4)$ & 0.18 & No & $29(10.5)$ & $24(21.4)$ & \multirow{2}{*}{$0.005^{*}$} \\
\hline & Yes & $257(87.7)$ & $92(83.6)$ & & Yes & $247(89.5)$ & $88(78.6)$ & \\
\hline
\end{tabular}




\section{Juniper Online Journal of Public Health}

\begin{tabular}{|c|c|c|c|c|c|c|c|c|}
\hline \multirow{3}{*}{ Knees } & No & $67(22.9)$ & $33(30)$ & 0.29 & No & $49(17.8)$ & $51(45.5)$ & P<0.001** \\
\cline { 2 - 9 } & Yes & $225(76.8)$ & $77(70)$ & & Yes & $226(81.9)$ & $61(54.5)$ & $36(32.1)$ \\
\hline \multirow{3}{*}{ Ankles } & No & $43(14.7)$ & $25(22.7)$ & $0.04^{*}$ & No & $32(11.6)$ & $3<0.001^{* *}$ \\
\cline { 2 - 9 } & Yes & $250(85.3)$ & $85(77.3)$ & & Yes & $244(88.4)$ & $76(67.9)$ & \\
\hline
\end{tabular}

*(Pearson chi-square, $\mathrm{P}<0.05),{ }^{* *}(\mathrm{Pearson}$ chi-square, $\mathrm{P}<0.001)$

\section{Discussion}

This study examined several important risk factors in professional drivers and their relationship with the occurrence of road accidents. Among the variables studied, only ergonomic risk factors showed significant relationship with the occurrence of road accidents. However the results of blood biochemistry tests such as cholesterol, triglyceride and FBS were worrying, because they indicate improper diet and little of physical activity among studied groups. On the other hands this situation increases risk of cardiovascular disease [6]. Nevertheless that the risk of hearing impairment of drivers described high in several researches, this study did not indicate any significant auditory threshold shift among drivers and no significant relationship was discovered between road accident and hearing ability of the drivers however Drivers who experienced road accident, showed weaker auditory sense [2].

The Nordic musculoskeletal questionnaire showed that symptoms from the musculoskeletal system were common among professional drivers studied. Based on the findings it may said that repeatedly drivers feel pain from the symptoms related to the lower and upper back parts, neck and knee that almost account for 25.2 and $18 \%, 21$ and $24.8 \%$ respectively , and it agrees with the existing literature [6]. Comparison of the results of this study with the results of the National Health Survey of Iran revealed that prevalence of musculoskeletal problems were higher in professional drivers to compare with general Iranian male population [20]. This indicates that professional driving should be considered as a high-risk occupation for developing musculoskeletal disorders. A professional driver is fundamentally constrained to the driver's cabin, which does not afford much room for flexing and comfort limb movements. A static posture aggravates accumulated muscle tension with lack of release. This is further deteriorated from prolonged periods on the role. As already established, backache in particular is a regular-reported strains of drivers, however other parts of pain origin from the neck, shoulder and knee [4].

The role of professional drivers can be a hazardous one, for musculoskeletal system health. Relatively few studies have been conducted on the relationship between road accident and musculoskeletal disorders of drivers. A number of studies have found relationships between occupational stressors evident in the job, with the well-being of professional drivers and safe performance. This study lends further support to this statement. On the basis of the obtained data it was found that musculoskeletal disorders especially in neck, upper back and ankles had positive association with road accident experiences of drivers. The results verify the idea that musculoskeletal disorders negatively impacts on safe operation of drivers. It may say that neck problems may influence visual performance by deviating of driver visual direction that may resulted into a road crash. Upper back has a close relationship with hands, so its disorder may interfere with driver manual operation on critical conditions. Ankles are the nearest driver body part to vehicle bottom devices such as pedals, so any uncomfortable situation of ankles stimulus on controlling responsibilities of drivers especially in life-threatening conditions. The road transport is a commercial where safety must be a main concern and therefore the relation between driver's musculoskeletal disorders and transportation accidents should deserve attention. So from this individual analysis, previous investigation has been confirmed.

Fatigue for drivers is usually apparent "when an individual cannot meet self-imposed or externally imposed performance goals but is forced to continue working under adverse conditions by a sense of duty and/or the need to safeguard the lives of others [4]. As demonstrated in the statistical analysis, fatigue and musculoskeletal health have a strong bearing on each other. This would seem to support the belief that fatigue affects musculoskeletal health. Such a conclusion thus means that by reducing job fatigue will have knock on effects on musculoskeletal structure, thus improving the health of drivers and consequence in less road mishap.

The personal unhealthy behavior of smoking was seen to be different from those drivers classed as suffering musculoskeletal disorders versus those drivers who didn't report any musculoskeletal illness. Smoking is frequently attributed to get rid of feelings of tension; nevertheless with the increasing alertness that tobacco use is related to a range of hostile health outcomes such as cancer; conceivably smoking is not as dominant today as it was in the past. Accordingly, drivers who might be under job stress may be looking towards other ways of handling job tensions, such smoking, as displayed in this study.

In the present study, continuous driving was associated with a higher chance of road accident. The observed association is meaningful to previous studies on other occupational groups often operating small automobiles. Walsh et al. found that driving a car or van for $4 \mathrm{~h}$ /day was associated with a high prevalence of low back pain in the previous 12 months [21]. Adam et al showed that extended work hours and further driven distance cause to a reduced amount of sleep in truck drivers. They reported that over half of their subjects having driven while drowsy or fallen asleep at the wheel through the earlier month [22]. 


\section{Juniper Online Journal of Public Health}

One of the less expected results of the present study was the lack of relationship between road accident and the age and working experience of the drivers. The most sensible account for this association is the so-called healthy worker effect [23]. It is known that drivers leave their occupation due to road crashes or they may lose their life due to the incident. Wellness programs are necessary to professional drivers, since they need to maintain a high level of physical fitness, manage and control their overall weight, select and adjust proper driver seating, and most of all take periodic breaks away from driving, during which they do some modest amount of exercises to break up the risk of musculoskeletal disorders. A successful workplace ergonomics program can significantly reduce the number and types of musculoskeletal injuries [15].

However, it is debatable to what extent professional drivers are alert of and have access to the research's results. Awareness of such work might assist them to collaborate with researchers to progress interventions that are evidence-based rather than ad-hoc efforts, and two specific areas for consideration are recruitment and administration strategies [24]. Our study may have been limited by shortcomings of the cross-sectional strategy. Even though we employed a generally used job-related study questionnaire to measure the prevalence of PMSC, the Nordic musculoskeletal questionnaire does not include detailed items that assess severity of musculoskeletal symptoms.

\section{Conclusion}

The main conclusion to be drawn from this study is that occupational ergonomic risk factors, smoking, pattern of driving period, age of vehicle as well as vehicle noise have close relationship with road accident in professional drivers. It can be said that musculoskeletal well-being influence the safe operation of drivers. On the other hand there is a close relationship between job fatigue and musculoskeletal problems. These associations should be further confirmed in prospective studies. However, even at the present stage, prevention strategies such as the transition to comfortable seats, better maintenance of vehicles, and organizational changes for reducing work-related stress are needed.

\section{References}

1. Af Wahlberg AE, Dorn L (2009) Absence behavior as traffic crash predictor in bus drivers. J safety Res 40(3): 197-201.

2. Karimi A, Nasiri S, Kazerooni FK, Oliaei M (2010) Noise induced hearing loss risk assessment in truck drivers. Noise Health 12(46): 49-55.

3. Sadri GH (2002) A Model of bus drivers disease: risk factors and bus accidents. IJMS 27(1): 39-41.

4. Tse JLM, Flin R, Mearns K (2006) Bus driver well-being review: 50 years of research. Transportation Research Part F: Traffic Psychology and Behaviour 9(2): 89-114.

5. Winkleby MA, Ragland DR, Fisher JM, Syme SL (1988) Excess risk of sickness and disease in bus drivers: a review and synthesis of epidemiological studies. Int J Epidemiol 17(2): 255-262.
6. John L, Flin R, Mearns K (2006) Bus driver well-being review: 50 years of research. Transportation Research Part F: Traffic Psychology and Behaviour 9(2): 89-114.

7. Hedberg GE, Jacobsson KA, Janlert U, Langendoen S (1993) Risk indicators of ischemic heart disease among male professional drivers in Sweden. Scand J work Environ Health 19(5): 326-333.

8. Celik O, Yalcın S, Ozturk A (1998) Hearing parameters in noise exposed industrial workers. Auris Nasus Larynx 25(4): 369-375.

9. Girard SA, Picard M, Davis AC, Simard M, Larocque R, et al. (2009) Multiple work-related accidents: tracing the role of hearing status and noise exposure. Occup Environ Med 66(5): 319-324.

10. Picard M, Girard SA, Simard M, Larocque R, Leroux T, et al. (2008) Association of work-related accidents with noise exposure in the workplace and noise-induced hearing loss based on the experience of some 240,000 person-years of observation. Accid Anal Prev 40(5): 1644-1652.

11. Kompier MAJ (1996) Bus drivers: Occupational stress and stress prevention. International Labour Office, Geneva, Switzerland.

12. Tamrin SB, Yokoyama K, Jalaludin J, Aziz NA, Jemoin N, et al. (2007) The association between risk factors and low back pain among commercial vehicle drivers in peninsular Malaysia: a preliminary result. Ind Health 45(2): 268-278.

13. Jensen A, Kaerlev L, Tuchsen F, Hannerz H, Dahl S, et al. (2008) Locomotor diseases among male long-haul truck drivers and other professional drivers. Int Arch Occup Environ Health 81(7): 821-827.

14. Chen JC, Chang WR, Chang W, Christiani D (2005) Occupational factors associated with low back pain in urban taxi drivers. Occup Med 55(7): 535-540.

15. Krueger GP (2007) Health and wellness programs for commercial drivers. Transportation Research Board, Washington Dc, USA.

16. Fourie C, Holmes A, Bourgeoism Bougrine S, Hilditch C, Jackson P (2010) Fatigue risk Management Systems: A review of the literature. Department for Transport, London, UK.

17. Horne J, Reyner L (1999) Vehicle accidents related to sleep: a review. Occupational and environmental medicine 56(5): 289-294.

18. Association AS-L-H (1997) Guidelines for audiologic screening. ASHA, USA.

19. Kuorinka I, Jonsson B, Kilbom A, Vinterberg H, Biering Sorensen, et al. (1987) Standardised Nordic questionnaires for the analysis of musculoskeletal symptoms. Applied ergonomics, 18(3): 233-237.

20. Choobineh A, Tabatabaei SH, Mokhtarzadeh A, Salehi M (2007) Musculoskeletal problems among workers of an Iranian rubber factory. J Occup Health 49(5): 418-423.

21. Walsh K, Varnes N, Osmond C, Styles R, Coggon D (1989) Occupational causes of low-back pain. Scand J work Environ Health 15(1): 54-59.

22. Hege A, Perko M, Johnson A, Yu CH, Sonmez S, et al. (2015) Surveying the Impact of Work Hours and Schedules on Commercial Motor Vehicle Driver Sleep. Saf Health Work 6(2): 104-113.

23. Krause N, Ragland DR, Fisher JM, Syme SL (1998) Psychosocial job factors, physical workload, and incidence of work-related spinal injury: a 5-year prospective study of urban transit operators. Spine 23(23): 2507-2516.

24.John L, Flin R, Mearns K (2004) Bus-ting a gut-the strains of an urban bus driver. In International Conference of Traffic \& Transport Psychology (ICTTP), Nottingham, England, UK, p. 1-11. 
This work is licensed under Creative Commons Attribution 4.0 Licens DOI: 10.19080/JOJPH.2017.01.555572

\section{Your next submission with Juniper Publishers will reach you the below assets}

- Quality Editorial service

- Swift Peer Review

- Reprints availability

- E-prints Service

- Manuscript Podcast for convenient understanding

- Global attainment for your research

- Manuscript accessibility in different formats

( Pdf, E-pub, Full Text, Audio)

- Unceasing customer service

Track the below URL for one-step submission https://juniperpublishers.com/online-submission.php 